\title{
ATUALIDADE DO DEBATE E EQUÍVOCOS METODOLÓGICOS DE “ADEUS AO PROLETARIADO” DE ANDRÉ GORZ
}

\section{TODAY'S DISCUSSION AND MISTAKES OF METHODOLOGY "THE GOODBYE PROLETARIAT" OF ANDRÉ GORZ}

\author{
Marcelo Gomes ${ }^{1}$
}

\section{RESUMO}

Nosso artigo pretende realizar uma abordagem crítica pouco explorada no debate sobre o livro Adeus ao Proletariado e sua tese sobre o fim do trabalho. Não visamos defender sua validade ou não, mas compreender os elementos metodológicos que levaram Gorz a abandonar quase completamente as teses centrais do marxismo. Este autor partilha um equívoco em comum com outros autores não dialéticos que compreendem de maneira simplista/linear a evolução das forças produtivas confundindo-se com a heterogeneidade e complexidade dos processos produtivos do século XX. Este é um dos motivos que levaram Gorz a propor um projeto emancipatório para além do trabalho social.

PALAVRAS-CHAVE: Trabalho - Taylorismo - Fordismo - Automação - Emancipação Gorz.

\begin{abstract}
Our paper aims to critically approach unexplored in the debate about the book Farewell to the working class and his thesis about the end of work. We aim not defend its validity or not but understand the methodological elements that led Gorz to abandon almost completely the central theses of Marxism. This author shares a misconception in common with other non dialectical authors who understand simplistically / linear evolution of the productive forces mingling with the heterogeneity and complexity of the production processes of the twentieth century way. This one of the reasons that leads Gorz to propose an emancipatory project beyond the social work.
\end{abstract}

KEYWORDS: Work - Taylorism - Fordism - Automation - Emancipation - Gorz. 


\section{INTRODUÇÃO ${ }^{2}$}

O debate sobre o trabalho enquanto conceito explicativo da sociedade ou demarcador do conceito de classe social, dentre outros temas correlatos, pode ser visto ao longo de toda segunda metade do século XX. No entanto, nenhum nos parece até hoje mais emblemático do que o livro de André Gorz, cujo elemento provocativo já está apontado em seu título: Adeus ao Proletariado. Este livro e suas teses principais já sofreram inúmeras críticas posteriores, inclusive no Brasil ${ }^{3}$. Todavia, não apenas o debate em torno do tema perdura, mas o próprio livro ocasionalmente figura em citações, o que demonstra que não se encontram de todo esgotados.

Tendo isso em vista, pretendemos aqui fazer uma abordagem que nos pareceu pouco explorada. A saber, se Gorz até então tinha uma grande influência em Marx, por que a dialética parece tão pouco presente em seu livro? Ao invés disso, ela parece ter se atrofiado em detrimento de um empirismo simplista que permitiu que seu autor ficasse refém das particularidades de seu contexto e, portanto, vinculado apenas ao plano fenomênico. Do mesmo modo, a ausência da visão dialética o faz - e a muitos outros autores também, incluindo aqui alguns de seus críticos - incapaz de perceber a contraditoriedade da evolução das forças produtivas e, destarte, ver as indústrias todas como uma totalidade homogênea cuja evolução se dá de modo linear.

A burguesia, na ânsia de reproduzir seu capital, não vê obstáculos morais e nem lógicos para combinar o que há de mais avançado ou atrasado na sociedade humana. Por isso, talvez, seja tão difícil definir o término deste debate. Afinal, o operário tradicional parece desaparecer (ao menos em suas roupagens) em alguns locais enquanto reaparece em outros. $\mathrm{O}$ conceito de trabalho produtivo e de proletariado parece encolher ou se expandir, dependendo da interpretação que se faça ou do método utilizado.

O capital é uma relação social contraditória e dinâmica, mas para além disso, há processos aparentes ou essenciais que se transpassam. Fenômeno e essência ora se misturam de modo homogêneo, ora se antagonizam. Por isso, ainda que num espaço exíguo, nossa pretensão neste artigo é colocar em relevo o aspecto metodológico deste debate. Pretendemos demonstrar como Gorz, prisioneiro de seu empirismo, deixa de compreender elementos fundamentais da teoria marxiana e, igualmente, deixa de discernir pontos fundamentais do processo produtivo capitalista e do potencial gerado pelo avanço das forças produtivas.

O livro de André Gorz Adeus ao Proletariado também possui alguns neologismos e se encontra eivado de ilogicismos e imprecisões conceituais. Por vezes, de forma quase 
aforística, busca resolver problemas complexos, enfraquecendo partes consideráveis de sua argumentação. Mas para evidenciarmos estes defeitos, devemos antes partir daquilo que serviu de fundamento das análises que levaram Gorz a mudar paulatinamente sua visão sobre o Marxismo e sobre a emancipação do proletariado.

\section{O PROCESSO QUE CONDUZ AO ADEUS AO PROLETARIADO}

O livro Adeus ao proletariado contém teses que não foram concebidas exclusivamente para esta obra. Elas são desdobramentos de concepções gestadas em obras precedentes do próprio autor. Estas obras, escritas nas décadas de 60 e 70 constituem uma clivagem na trajetória teórica de Gorz que se vê influenciado pelos acontecimentos do contexto europeu neste período ${ }^{4}$. Estas transformações - no contexto e no autor - refletemse diretamente na visão e no projeto dualista emancipatório contido no livro Adeus ao proletariado. Daí a importância de nos determos neste elemento particular e empírico que influencia o autor e, deste modo, compreendermos uma chave explicativa para as razões das polêmicas suscitadas por esta obra.

As obras de Gorz até a década de 70 refletem sua preocupação com a esquerda e seu projeto político revolucionário que eram, ambos - e segundo sua visão comprometidos integralmente com o crescimento econômico do período do pós-segunda guerra. Período este marcado pelo apogeu do capitalismo numa era economicamente virtuosa - ao menos na parcela dos países desenvolvidos - conhecida como anos dourados, "um período homogêneo único na história do mundo", para concordar com Hobsbawm (2000). Período cuja estratégia de reprodução do capital estava fundada na produção em massa e no uso do trabalho vivo em larga escala nas fábricas taylor-fordistas, o chamado mass-collective worker. Um momento de expansão e domínio do setor metalmecânico que consumia muita mão de obra desqualificada ou semi-qualificada. Lembremos as declarações do próprio Ford ${ }^{5}$ :

Quanto ao tempo preciso para a aprendizagem técnica a proporção é a seguinte: $43 \%$ não requerem mais que um dia; 36 requerem de um dia até oito; 6 , de uma a duas semanas; 14, de um mês a um ano; 1, de um a seis anos. Esta última categoria de trabalhos requer grande perícia - como a fabricação de instrumentos e a calibragem (FORD, 1926, p. 105). 
Daí a principal indagação crítica de Gorz recair sobre a desqualificação e perda de autonomia, bem como a suposta imanência do caráter revolucionário do proletariado que neste momento participava da integração econômica, via políticas keynesianas. Isso teria feito com que sua força revolucionária arrefecesse de tal modo que seria imperativo pensar em novas estratégias políticas mais graduais e reformistas (ainda que reivindicando o socialismo).

O que o autor deixa claro, nesta fase de sua obra, é que a esquerda francesa deveria abdicar das tradicionais formas de luta pelo socialismo para empenhar-se na busca por "reformas revolucionárias", que fariam com que as vitórias parciais conquistadas pelos trabalhadores conduzissem à triunfal superioridade do socialismo sobre o capitalismo, aos olhos de todos (PRIEB, 2005, p. 41).

Estas preocupações iniciais se somam a outras na década de 70 e finalmente 80 , momento no qual o livro Adeus ao Proletariado é escrito ${ }^{6}$. São partes integrantes deste contexto os temas do despotismo de fábrica e, correlato a isso, da hierarquização e disciplinarização condicionadas desde as escolas ${ }^{7}$. Nisso, Gorz acompanha uma tendência cujo epicentro se deu no maio de 68 na França, no qual o estruturalismo parecia triunfante e o repúdio a todas as instituições sociais (precipuamente a fábrica, a família, a escola) estava na ordem do dia. O ecologismo ensaia aqui seus primeiros passos. E ainda neste período suspeitava-se também que nenhuma sociedade futura poderia surgir das bases institucionais viciadas do capitalismo. Daí derivarem também os temas da crítica às forças produtivas ${ }^{8}$ e, com ela, de parte considerável da teoria materialista da história, para a qual as contradições que fazem emergir novas formas sociais se encontram entre as forças produtivas progressistas e as relações sociais de caráter conservador. Por fim, já na década de 80, a estes temas se soma a sensação de impossibilidade de retomar a autogestão e a autonomia dentro do universo do trabalho necessário, o qual exige um complexo produtivo que não se prestaria a este objetivo humanista. Igualmente, uma composição de classe tradicional (o que restou de proletariado segundo Gorz) que não mais expressa o futuro libertador, mas um passado aprisionador. Dentro da esfera do trabalho necessário a regulação é preponderantemente heterônoma e só uma classe excluída (a não classe) em uma esfera de atividades marginais é que poderia reivindicar a autonomia perdida. Neste sentido, Gorz pode ser traçado em paralelo à Habermas e sua teoria da ação comunicativa. Ambos, sofrendo aqui uma maior influência não de Marx, mas de Weber, o que torna sintomático dos desvios do campo teórico marxista. 
Todavia, todas estas transformações teóricas que se cristalizam em Adeus ao proletariado são frutos de um mergulho de Gorz em seu tempo e em seu contexto. Nesse sentido, o autor jamais poderia ser acusado de idealismos, ainda que o seja por efeito de suas conclusões. Seu empirismo o torna prisioneiro da particularidade europeia e dos fenômenos emergentes que ocultam processualidades contraditórias que não aparecem no nível positivo grosseiro tomado. Vejamos então a contraditoriedade e, igualmente, partes e causas fundamentais destes equívocos ao revisitar o contexto que o influencia.

\section{APOGEU E CRISE DA SOCIEDADE DO "TRABALHO"9}

Praticamente as três décadas que se seguiram ao pós-guerra foram marcadas por um profundo crescimento da economia mundial. Foi o que os economistas classificaram como um período de boom do capitalismo. Boa parte deste sucesso fora vista na época, pela maioria dos analistas, como uma decorrência direta da política econômica estatal conhecida como keynesianismo, na qual o Estado assumia a função de maior agente econômico e responsável direto por investimentos e pela dinâmica da economia ${ }^{10}$. Os países capitalistas haviam aprendido - com a economia de guerra de um lado e a economia planificada da União Soviética de outro - a controlar o mercado e a colocá-lo em confluência com os objetivos estatais. Esta política apostava num crescimento gerado pela ação do Estado garantindo gastos públicos que estimulariam a economia. Dessa forma, poder-se-ia esperar certa indução e aumento de demanda efetiva. Assim, "passava a existir uma economia de consumo de massa com base no pleno emprego e rendas reais em crescimento constante, escorada pela seguridade social, por sua vez paga pelas crescentes rendas públicas" (HOBSBAWM, 2000, p. 277). De fato, como pudemos ver, o crescimento do consumo de bens duráveis no pósguerra foi algo de espantoso (HOBSBAWM, 2000).

É justamente neste período que veríamos o crescimento das técnicas de propaganda e indução ao consumo promovidas de forma sistemática através dos nascentes meios de comunicação de massa, a mass media. Houve também um visível crescimento da "classe média" que, como nos mostra HOBSBAWM em seu livro, ilustraria com perfeição um estrato social altamente influenciado pela burguesia e seus interesses, dando origem aos consumidores compulsivos hodiernos motivados pela ideologia consumista: 
Ao mesmo tempo, o compromisso político de governos com o pleno emprego e em menor medida - com redução da desigualdade econômica, isto é, um compromisso com a seguridade social e previdenciária, pela primeira vez proporcionou um mercado de consumo de massa para bens de luxo que agora podiam passar a ser aceitos como necessidades (HOBSBAWM, 2000, p. 264).

Com a ampliação da massa salarial e o aumento do consumo, a demanda por bens duráveis fortaleceu ainda mais a indústria metalmecânica. Sabemos, contudo, que boa parte desta indústria, entendida como indústria de forma (assembly industry), se valia de mão-deobra em larga escala, como é característico dos processos produtivos tayloristas e fordistas.

Sendo assim, a indústria paradigmática acaba se tornando, acertadamente ou equivocadamente, a automotiva. Womack, Jones e Roos abrem seu livro A Máquina que Mudou o Mundo com a seguinte frase a respeito da indústria automotiva:

Quarenta anos atrás, Peter Drucker denominou-a de "a indústria das indústrias". Atualmente, a indústria automobilística continua sendo a maior atividade industrial, com aproximadamente 50 milhões de novos veículos produzidos a cada ano (WOMACK; JONES; ROOS, 1992, p. 1).

Vê-se, por este relato, o grau de importância dado à indústria metalmecânica e, especificamente neste caso, ao setor automotivo, por uma série de autores que analisam o processo de trabalho no século XX. Por este peso e pelo contingente de trabalho demandado é que podemos explicar seu impacto tanto na economia quanto na formatação do imaginário sociológico que ilusoriamente o cultivou como o paradigma produtivo generalizável aos vários processos de produção. Poderemos ver à frente que no período do pós-guerra ocorreu um forte crescimento na demanda de bens de produção e bens de consumo duráveis, dentre estes, o automóvel. Na verdade, na primeira metade do século este produto já despontava como um importante atrativo de consumo. Mas foi graças a Ford e seu empenho obsessivo que este produto pôde sair de uma produção quase artesanal (craft-production) no início do século para se tornar o produto de massa par excellence do pós-guerra. E não fora somente o automóvel. Toda uma mudança no padrão de consumo (principalmente o americano) demandou bens como eletrodomésticos e outros bens de consumo duráveis, assim como os bens de capital para a produção de tais produtos.

Al analizar el contenido sectorial de la expansión industrial, se comprueba que hay dos grandes familias de productos que ejercen el liderazgo indiscutido en la estructura industrial: la de los productos pertenecientes a la metalmecánica y la rama química, en particular la petroquímica. En la metalmecánica están incorporados los 
bienes de capital, los bienes de consumo durables domésticos y los automóviles. Tanto el sector automotor como los bienes de consumo durables simbolizan en buena medida, el patrón de consumo prevaleciente en los Estados Unidos y en ellos se advierte, como se verá más adelante, una tendencia paulatina de aproximación de Europa y Japón a los niveles norteamericanos (FAJNZYLBER, 1983, p. 22, grifo nosso).

A produção de todos estes bens estava baseada nas técnicas e processos tayloristas e/ou fordistas, o que impulsionou o impacto econômico deste setor (MORAES NETO, 2003, p. 32). Daí que não se explica, a nosso ver, o sucesso dos anos dourados apenas pela adoção das políticas keynesianas, mas por aquilo que talvez tenha possibilitado a implantação com sucesso destas políticas: a principal indústria deste período - metalmecânica — demandava muitos trabalhadores. O ciclo virtuoso, do período keynesiano e do Welfare State, constituído por crescimento econômico, liquidez, aumento da demanda efetiva, arrecadação, gastos sociais, pacto social estaria garantido, não fossem as transformações nas forças produtivas impactarem com as relações sociais fortemente integradoras. Integração, esta, que era o passaporte para desfrutar das benesses desta economia e que, ipso facto, serviram para Gorz ver a falência das estratégias tradicionais marxistas.

Mas a demanda por emprego não ocorre de forma homogênea nas indústrias metalmecânica, têxtil, petroquímica etc. Por isso, a extensão desta primeira impacta e muito nas análises sociológicas de muito autores que pensam o século $\mathrm{XX}$, ainda que o que nos importe aqui seja apenas Gorz. Assim, podemos estabelecer um comparativo da extensão desta indústria ao longo dos "anos gloriosos".

En 1955, los productos químicos y derivados representaban, a nivel mundial, el 10 $\%$ de la producción industrial. En 1977, esa producción se había elevado al 14 \%. La industria metalmecánica eleva su participación de 34 a $43 \%$ en ese mismo período (FAJNZYLBER, 1983, p. 22).

Ou seja, em 1977 a industria metalmecânica compreende praticamente metade de toda a economia produtiva mundial. E uma vez que para a produção destes bens de consumo duráveis a burguesia despendia uma grande soma em capital variável, então se torna clara a relação entre a organização do trabalho baseada no taylorismo/fordismo e o pleno emprego vivenciado nos períodos de crescimento dos anos dourados do capitalismo ${ }^{11}$. De qualquer forma, a sociedade capitalista vivenciaria por algumas décadas o fenômeno deste pleno emprego, fato que teria levado muitos pensadores da época a considerarem que o desemprego e a pauperização vaticinada por Marx como uma lei inexorável do capital fosse mais uma de 
suas infundadas "escatologias catastrofistas". "Desemprego em massa? Onde se poderia encontrá-lo no mundo desenvolvido da década de 1960, quando a Europa tinha uma média de $1,5 \%$ de sua força de trabalho sem emprego e o Japão 1,3\%" (HOBSBAWM, 2000, 262).

Este contexto teria então influenciado profundamente André Gorz no seu primeiro percurso teórico, no qual traçaria uma estratégia operária de tomada e controle do processo de produção. Pelo menos é isso que podemos ver no livro de Josué Pereira da Silva:

O ambiente histórico e político no qual Gorz começou sua carreira intelectual é o complexo contexto europeu e particularmente o francês das décadas de 1950 e 1960. Esse contexto caracterizou-se, de um lado, pela crise do stalinismo e, de outro, pela estabilização do capitalismo no Ocidente e pelos sucessos do welfare state keynesiano, que levaram a uma pacificação dos conflitos de classe nos países desenvolvidos do Ocidente. É no interior desse contexto que deve ser entendida a teoria de Gorz sobre estratégia operária. (SILVA, 2002, p. 130).

Não obstante, duas décadas mais tarde o contexto mudaria radicalmente no que tange o crescimento econômico e o desemprego. Esta crise marca o término da vigência ampla do Welfare State, o que ocorre de forma concomitante - ou até mesmo em consequência - à entrada da automação de base microeletrônica no plano produtivo. Estes dois fenômenos, a nosso ver interligados, redundariam no que foi chamado de "crise da sociedade fundada no trabalho" que, efetivamente, não passa da crise de uma sociedade fundada na extração e valorização pelo trabalho abstrato.

\begin{abstract}
A abolição do trabalho é um processo em curso e que parece acelerar-se. Para cada um dos três principais países industrializados da Europa Ocidental, institutos independentes de previsão econômica estimaram que a automação irá suprimir, no espaço de dez anos, entre quatro e cinco milhões de empregos, a menos que haja uma revisão profunda da duração do trabalho, das finalidades da atividade e de sua natureza. Keynes está morto: no contexto da crise e da revolução tecnológica atuais, é rigorosamente impossível restabelecer o pleno emprego [...] (GORZ, 1987, p. 11).
\end{abstract}

À época da formulação das teses de seu livro, os efeitos da crise e das novas tecnologias de automação no nível de emprego já se faziam sentir de forma avassaladora. $\mathrm{O}$ desemprego em massa que poderíamos ver pelas décadas subsequentes aos anos gloriosos do capitalismo iria marcar fortemente André Gorz, a ponto deste fenômeno fornecer o título para sua obra. Este desemprego, causado principalmente pela crise e pela inserção da automação no processo de produção de setores importantes, teria sua taxa rapidamente elevada, como podemos ver: 
O desemprego na Europa Ocidental subiu de uma média de 1,5\% na década de 1960 para 4,2\% na de 1970 (Van der Wee, 1987, p. 77). No auge do boom em fins da década de 1980, estava numa média de 9,2\% na Comunidade Européia, em 1993, $11 \%$. Metade dos desempregados (1986-7) se achava sem trabalho há mais de um ano, um terço há mais de dois (HOBSBAWM, 2000, p. 396).

E ainda que a crise seja vista nesse momento como a geradora do desemprego é preciso entender que a evolução das forças produtivas possui ação direta, no nível de emprego e, por que não, na própria crise, a tal ponto que este desemprego deve ser visto, sobretudo, como um desemprego tecnológico. E por isso a retomada do crescimento na economia pouco poderia ajudar para a retomada dos índices de empregabilidade em vários setores ${ }^{12}$.

O número de trabalhadores diminuiu relativamente, absolutamente e, em qualquer caso, rapidamente. $\mathrm{O}$ crescente desemprego dessas décadas não foi simplesmente cíclico, mas estrutural. Os empregos perdidos nos maus tempos não retornariam quando os tempos melhoravam: não voltariam jamais (HOBSBAWM, 2000, p. 403).

Este descompasso entre crescimento e nível de emprego na era da automação microeletrônica Gorz bem o sabia, e afirmava:

Na idade da automatização, o crescimento deixa de ser gerador de emprego. A maior parte das indústrias, na verdade, podem ou poderão produzir mais reduzindo seu pessoal. Na Alemanha [...] aproximadamente a metade (46\%) de todos os investimentos industriais visam precisamente a essa finalidade: "economizar mãode-obra" (GORZ, 1987, p. 161).

Desse modo, romper-se-ia

[...] o laço entre crescimento da produção e crescimento do emprego. Põe em maus lençóis um dos dogmas da economia política keynesiana, a saber: que a retomada do investimento reduzirá o desemprego.

Keynes morreu e com ele as políticas do "pleno emprego" (GORZ, 1987, p. 161).

Acompanhando este processo, podemos ver que Gorz presencia a ascensão de uma sociedade do pleno emprego capaz de cooptar o proletariado e integrá-lo a tal ponto dele, Gorz, julgar que este perderia com isso seu impulso revolucionário. Pouco tempo depois, vê a destruição deste mundo integrador pela introdução de métodos produtivos automatizados. Mas mesmo assim, não vê a destruição do taylorismo e do fordismo e julga que de um lado temos o resultado da automação: um "neoproletariado" formado pelos excluídos da produção 
e por aqueles que se sustentam de forma ocasional em empregos agora desregulamentados, parciais ou temporários. E de outro lado, ainda teríamos uma "elite" trabalhadora constituída em níveis hierarquizados cujo trabalho tem como característica a heteronomia de uma produção desqualificada, parcelar e concebida ainda por uma gerência, cuja estrutura é típica do taylorismo e do fordismo.

Portanto, sobre a visão de Gorz não recai apenas o limite de não conceber o sistema capitalista como uma totalidade composta por processos combinados e desiguais ${ }^{13}$. Do contrário, poderia perceber que a tese do "fim do trabalho" é por demais simplista se aplicada como generalização do mundo europeu para o restante do sistema capitalista que vivenciava neste momento a transnacionalização e financeirização de sua economia ${ }^{14}$. Sobre esta visão recai também a contradição de perceber dois movimentos antitéticos como tendência, ao invés de ver um movimento como tendência e outro como passado residual. E isto porque Gorz não concebia a produção como um todo contraditório que teria no seu nível mais evoluído a imagem do menos evoluído, tal como apregoava a metáfora metodológica dialética da comparação entre a anatomia do homem e do macaco por Marx e Engels. Afinal, no que tange a produção, a indústria metalmecânica se encontrava em seu anacronismo no século XX até a década de 80 com a inserção da microeletrônica e informática. É mister compreender que outras indústrias e setores já caminhavam pelos princípios da automação desde o começo do século XX e mesmo século XIX. Este é o caso do setor têxtil e do setor chamado de indústria de fluxo ou processos contínuos, ambos contendo um alto grau de automação determinada pela aplicação tecnológica da ciência ${ }^{15}$.

Parece também que a visão de Gorz, em geral pouco dialética, tenha compreendido a evolução das forças produtivas como um processo linear e homogêneo entre diferentes indústrias e setores. Assim, a aplicação mecânica e genérica dos critérios fenomênicos descritos nos capítulos XI, XII e XIII de $O$ Capital pode sugerir que todas as indústrias passam ao mesmo tempo pela evolução da cooperação simples, divisão parcelar e grande indústria automatizada. Para os que veem a evolução de tal forma é impossível compreender que setores tenham chegado à automação já no século XIX enquanto a indústria de forma e de montagem, como a automobilística, só tenha começado seu processo na década de 80 do século XX, ainda que nos processos mecânicos de fabricação o tenha feito a partir da década de 60 do mesmo século com a rigidificação das $\mathrm{MFUs}^{16}$ até a flexibilidade das $\mathrm{MFCNCs}^{17}$. 
O revolucionamento ocasionado pela introdução da nova automação, de base microeletrônica, sobre a forma taylorista-fordista de produzir concentra-se, portanto, na indústria metalmecânica produtora de bens duráveis de consumo complexos. Sua conseqüência será a de trazer essa indústria para o "leito da automação", no qual já caminham há muito tempo ramos industriais tecnologicamente mais avançados, como as indústrias têxtil e de processo contínuo (MORAES NETO, 2002, p. 83-4).

Possivelmente, o peso da indústria metalmecânica e automotiva naquele período tenha influenciado Gorz a tal ponto de não perceber este descompasso e, pior, ter-se sugerido que a relação taylorista e fordista não encontraria limites, compondo esta dualidade que marcaria o mesmo dualismo em seu projeto emancipatório - trabalho necessário e social heterônomo e desqualificado de um lado e, fora dele ${ }^{18}$, autônomo, mas individual e

espontâneo. É o que se vê nesta passagem em que Josué reafirma a visão de Gorz sobre a impossibilidade de emancipação: "A eliminação do trabalho, de um lado, e a persistência de uma divisão do trabalho alienante, de outro, solapam a possibilidade de controle operário e impedem a possibilidade de libertação no trabalho" (SILVA, 2002, p. 204).

\section{O EMPIRISMO DE GORZ E O IDIOTISMO DA PROFISSÃO}

Gorz tem o olhar fixo para os processos de trabalho e sua transformação no período tratado acima. Mas seu empirismo desmedido primeiro o conduz ao equívoco urbi et orbi, ou seja, o que é válido para seu contexto deve ser válido para o mundo todo. Além deste desvio, outro defeito deste empirismo descuidado é como falamos, confundir processos produtivos distintos. O taylorismo e o fordismo aparecem enquanto fenômeno para suprirem uma necessidade imperiosa do capital de controlar o trabalhador em processos nos quais este é o elemento principal. Onde o capital conseguir, aplica-se a subsunção real do trabalho e onde não se conseguir esta primeira, aplica-se a subsunção formal. Foi o que Taylor e Ford fizeram.

O capital visa, se puder, a exclusão do trabalhador do processo. Enquanto não se consegue, tal como em Taylor e Ford, a estratégia é: fracionar o trabalho, retirar todo seu conteúdo de concepção e passá-lo para a gerência (MORAES NETO, 1991).

Os princípios de "organização científica” tayloristas não são nada extraordinários. Após vencer um período de resistência por parte dos trabalhadores, Taylor consegue com êxito passar o comando e o conhecimento de como fazer para a gerência decidir pelo trabalhador. Isso é o que Gorz acusa como perda de autonomia. Mas isso não deve ser 
confundido com a falência da tese marxiana de relações sociais superiores brotando do desenvolvimento ao limite das forças produtivas no capitalismo. Afinal, estes processos demonstram antes a mediocridade do que o caráter revolucionário do desenvolvimento tecnológico capitalista. Como podemos ler em Braverman,

[...] Taylor não estava interessado a princípio no avanço da tecnologia [...]. Ele fez significativa contribuição para o conhecimento técnico da prática nas oficinas (sobretudo no aceleramento do manejo de ferramentas), mas se trata de subprodutos de seu empenho em estudar esta prática com vistas a sistematizá-la e classificá-la. Interessava-lhe o controle do trabalho em qualquer nível de tecnologia (BRAVERMAN, 1977, p. 101).

A saída apresentada foi justamente promover ainda mais a desqualificação através da simplificação dos tempos e movimentos, com sua posterior passagem para o controle da gerência. Ford, seguindo os mesmos preceitos de Taylor, inova o mesmo por levá-lo ao seu paroxismo. E, como já dissemos uma vez empregadas em larga escala na indústria metalmecânica que se expandiam vertiginosamente naquele período, as técnicas tayloristas e fordistas se tornariam simbolicamente hegemônicas no seio da moderna sociedade industrial, a tal ponto que estas técnicas foram vistas como ilustrativas das forças produtivas do capitalismo. Criticá-las tornou-se análogo à crítica dirigida ao capital. Ao mesmo tempo, criticar o capital seria análogo à crítica ao taylorismo/fordismo.

[A partir do livro de Piore e Sabel, de 1984] [...] torna-se possível enxergar fordismo em qualquer [lugar] da manufatura ao longo dos últimos 60 anos. Contra isso, argumentamos que a inovação de Ford da fábrica com linha de montagem possui um campo limitado de aplicação... As técnicas produtivas de Ford apenas apresentam uma esmagadora vantagem de custo na produção de bens duráveis complexos, inicialmente automóveis e produtos elétricos, e posteriormente no campo de produtos eletrônicos, os quais incluem bens de consumo e de produção. [...] Todavia, para o caso dos bens de consumo simples, como vestuário e móveis, as técnicas de produção em massa possuem uma vantagem limitada. As indústrias de processo, intensivas em capital, como siderúrgicas e químicas, seguiram por um caminho próprio antes e depois de Ford. É portanto bastante compreensível que a maior parte das plantas nas economias avançadas não contenham linhas de montagem; o mencionado levantamento sobre a indústria manufatureira britânica mostrou que $31 \%$ das plantas da amostra utilizam linhas de montagem, e apenas metade delas acionadas mecanicamente. As inovações de Ford foram importantes, mas elas dificilmente podem-se responsabilizar por toda trajetória de desenvolvimento das economias avançadas (WILLIAMS et al. apud MORAES NETO, 2003, p. 95, grifo do autor). 
No entanto, o que seria realmente mais grave no campo propriamente conceitual é que esta generalização do taylorismo/fordismo fez com que estas técnicas fossem vistas como a consubstanciação da grande indústria descrita por Marx. E é a partir deste princípio equivocado que podemos ver ilações abstrusas como esta em que Coriat identifica taylorismo como a realização da grande indústria descrita por $\operatorname{Marx}^{19}$.

"Tudo o que Marx anuncia relativamente às características especificamente capitalistas do processo de trabalho (parcelamento das tarefas, incorporação do saber técnico no maquinismo, caráter despótico da direção) o realiza Taylor, ou mais exatamente, lhe dá uma extensão que até então não havia tido. O excepcional interesse que apresenta Taylor reside no fato de que é a expressão consciente, concentrada e sistemática dos interesses do capital em um momento estratégico de sua história. Torna consciente a burguesia dos imperativos da valorização do capital relativos às formas que devem imprimir ao processo de trabalho, formas que Marx havia anunciado de maneira dedutiva" (CORIAT apud MORAES NETO, 1991, p. 94, itálico do autor).

Assim, para vários autores, bem como para André Gorz, olhar para as forças produtivas mais desenvolvidas do capitalismo significaria fundamentalmente olhar para o locus produtivo da indústria metalmecânica (e em grande medida a indústria automobilística) e sua característica específica de organização do trabalho: o taylorismo e o fordismo. Gorz estaria muito longe do entusiasmo de Marx nos seus Grundrisse ao avaliar a importância de uma base tecnológica desenvolvida, pela mediação da científica, para a emancipação humana. E assim a autonomia entendida como possibilidade de fazer e agir sem determinação prévia de um protocolo técnico e de um corpo de gerentes ficava comprometida.

[...] mesmo que as tarefas repetitivas e embrutecedoras sejam abolidas ou, quando não possam sê-lo, sejam repartidas por toda a população, o trabalho socialmente necessário nunca será comparável à atividade dos mestres-artesãos ou dos artistas; uma atividade autodeterminada, de que cada pessoa ou equipe define soberanamente as modalidades e o objeto, o toque pessoal, inimitável, que imprime sua marca particular ao produto (GORZ, 1987, p. 17).

E para alguém como Gorz que nutria uma inconfessa, mas explícita, apologia do ideal passadista artesanal e, igualmente, para alguém que não fazia distinção das técnicas e tecnologias e seus potenciais distintos, o sonho da autogestão e da emancipação estaria para sempre comprometido. Dentro do trabalho, a heterodeterminação taylor-fordista seria denunciada. Enquanto a automação seria acusada pela "terrível" consequência de fazer o óbvio: eliminar o trabalho! E neste sentido, Gorz evidencia uma tendência, também inconfessa, muito similar à Proudhon. E por isso a mesma crítica de Marx a este serve àquele: 
A oficina automática faz desaparecer as espécies e o idiotismo da profissão.

O sr. Proudhon, não tendo sequer compreendido este único aspecto revolucionário da oficina automática, dá um passo atrás, e propõe ao operário que faça não apenas a duodécima parte de um alfinete, mas sucessivamente todas as doze partes. $\mathrm{O}$ operário chegaria assim à ciência e à consciência do alfinete. [...].

Resumindo, o sr. Proudhon não superou o ideal do pequeno-burguês. E para realizar esse ideal, não imagina nada melhor do que fazer-nos voltar ao companheiro ou, quando muito, ao mestre-artesão da Idade Média (MARX, 2001, p. 126-7).

Infelizmente, Gorz e os teóricos burgueses não foram os únicos a confundir o taylorismo (e fordismo) como o mais alto avanço das forças produtivas capitalistas. Lênin, sendo ou não parte de uma tática conjuntural, endossa o mesmo equívoco e, por isso, Gorz poderia olhar tanto para o capitalismo como para os processos revolucionários socialistas que extrairia as mesmas consequências. Lênin, que até 1918 atacava fortemente o taylorismo como a "forma de extração de mais suor do trabalhador" declarou:

A última palavra do capitalismo neste terreno — o sistema Taylor — do mesmo modo que todos os avanços do capitalismo, reúne em si toda a ferocidade refinada da exploração burguesa e uma série das maiores conquistas científicas referentes ao estudo dos movimentos mecânicos durante o trabalho, a supressão dos movimentos supérfluos e torpes, a elaboração de métodos de trabalho mais racionais, a implantação de melhores sistemas de registro e de controle, etc. A República Soviética deve adotar, a qualquer custo, as conquistas mais valiosas da ciência e da técnica neste domínio. A possibilidade de se construir o socialismo depende precisamente do êxito que logremos, ao combinar o poder soviético e a organização soviética da direção com as últimas conquistas do capitalismo (LENIN, 1988, p. 164, grifo nosso).

As necessidades imediatas do poder soviético exigiram medidas extremas tanto neste período como na década de 30, com a coletivização forçada stalinista. A emulação socialista, as brigadas de choque de trabalhos em infraestrutura e o stakhanovismo, dentre outros elementos, ampliam os exemplos que permitem a mesma conclusão que se fazia ao olhar para a exploração do trabalho nos países capitalistas. Por isso, o olhar de Gorz por todo este período the forneceria o reforço para seu projeto dualista. Um projeto fundado num duplo equívoco. 1) conceber as forças produtivas de maneira indistinta. 2) Não perceber o potencial emancipador fornecido pela automação (seja de base eletromecânica ou microeletrônica, flexível ou dedicada) e pela informática.

O conceito emancipatório ${ }^{20}$ e o de "homem" em Marx $^{21}$ não estão fundados num indivíduo que se realiza fazendo seu trabalho isolado do começo ao fim, mas muito mais na mediação complexa que envolve a produção e que lhe confere um teor científico que obriga e impõe o enriquecimento cultural como conditio sine qua non para esta tarefa. 
Os trabalhos realmente livres - o [trabalho] da composição musical, por exemplo - são ao mesmo tempo endiabradamente sérios e requerem o esforço mais intensivo. O trabalho da produção material só pode assumir este caráter: 1) se tem assegurado em si seu caráter social, e 2) se tem um caráter científico e é, ao mesmo tempo, de caráter geral, e não o esforço de um homem como uma força natural domesticada, mas [o trabalho] de um sujeito que atua no processo de produção como uma atividade reguladora de todas as forças naturais, e não em uma forma puramente natural e primitiva (MARX, 1985b, pp. 33-4).

Portanto, ser livre, diferentemente do senso simplório que parece permear as pretensões de Gorz, não é produzir o que se quer ou da maneira que se quer no momento que se quer, mas no suprassumir-se da sua própria condição natural que é inerente a cada individualidade crua. Uma produção emancipadora deve necessariamente exigir igual dimensão de apropriação. Só assim o indivíduo deixa esta condição natural para se tornar parte integrante do gênero e, portanto, do ser social — projeto só possível a partir de relações sociais cujo fundamento não seja a apropriação privada e acumulação abstrata da riqueza.

\section{CONCLUSÃO}

Tendo em vista o princípio de que a consciência, como na reviravolta copernicana e compreendida corretamente, não guia, mas é guiada pelas condições matérias que a cercam, podemos supor compreensível que no contexto do vigor do capital financeiro autores até sérios tenham se deixado levar pela miragem de que a riqueza pode se reproduzir independente do lastro material e dos homens. Sendo assim, a tese do fim da importância do trabalho material para a criação de riqueza foi o mote deste fim de século, precipuamente na sociologia.

Do exposto, podemos concluir que os anos 50 e 60, período do pleno emprego, do uso extensivo do trabalho vivo, do cooptação do pacto social keynesiano etc. determinaram em Gorz a postura de buscar um caminho intermediário entre a revolução e o gradualismo da social-democracia, apostando ainda num socialismo coletivamente gerido pela classe trabalhadora. Os anos 70 demarcam uma ruptura com este pensamento que culmina nos anos 80 com a publicação de Adeus ao Proletariado, no qual o proletariado tradicional deixa de ser visto como sujeito, tomando seu lugar o "neoproletariado" formado por desempregados, trabalhadores parciais e precarizados pelos efeitos das novas tecnologias e reestruturação produtiva. 
A partir desta obra, fica claro que seu olhar empírico se tornou prisioneiro das transformações ocorridas no nível fenomênico. Gorz não reconhece a heterogeneidade das indústrias de fluxo, têxteis, metalmecânica etc. e por isso vê taylorismo e fordismo em tudo, juntamente com a desqualificação inerente a estes processos. Quando, em raros momentos do seu livro, concebe processos produtivos distintos destes e concordantes com as descrições mais ousadas de Marx nos Grundrisse - nas quais a mediação da ciência torna o processo complexo e exige do homem maior qualificação e apenas um trabalho de supervisão — Gorz também faz a crítica a estes sistemas automáticos, não mais porque desqualificam, mas porque é o trabalho acumulado na tecnologia que realiza todas as atividades, vendo aí de modo fetichizado a impotência do indivíduo trabalhador. Assim, vê-se que o problema da emancipação não se encontra nas forças produtivas mais avançadas, mas no próprio paradigma emancipatório de Gorz que, indisfarçadamente, revela seu apego passadista às formas artesanais de produção. Louva o trabalho e o indivíduo no seu isolamento fabril, elementos típicos do trabalho dos artífices das corporações de ofício no feudalismo, é preciso dizê-lo.

Gorz, então, passa a aceitar uma heteronomia e uma alienação insuperáveis - e até mesmo uma relação capitalista produtora de mercadorias - desde que haja espaço para uma produção marginal autônoma - correlata a muitas das propostas da chamada escola de economia solidária. Afinal, a automação poderia permitir que os excluídos operassem em outra esfera. As grandes indústrias assumiriam o trabalho necessário social, permitindo que os indivíduos excluídos ou parcialmente excluídos pelos efeitos da reestruturação produtiva possam se dedicar aos trabalhos voluntários e individuais, sem qualquer compromisso com a produção social. Quiçá o discurso sobre o empreendedorismo seja sua cobertura ideológica atual.

Esta visão superficial e pouco dialética leva Gorz (e tantos outros) ao simplismo e limite do empirismo sociológico grosseiro, tendo como efeito a incompreensão de Marx tanto quanto a diferença entre determinação social particular das forças produtivas e sua real essência. ${ }^{22}$ Do mesmo modo, a crítica que se fez a Marx neste período só faz por revelar a própria nudez do acusador. A visão dialética impedia Marx de ser um catastrofista e, mais ainda, naturalizar as relações sociais e unilateralizar o desenvolvimento humano - tal como a tese weberiana da jaula de ferro ou parte das críticas frankfurtianas - como se fez transparecer em teses e títulos como "homem unidimensional".

A hegemonia da metalmecânica e dos processos produtivos tayloristas e fordistas (ou ohnoístas) causou estrago considerável na teoria revolucionária quando estes foram 
entendidos como o mais alto avanço científico em termos produtivos - mesmo Lênin se equivocou. Estes processos produtivos medíocres, lastreados na ergonomia e no papel central do homem - e mesmo o trabalhador enquanto apêndice da máquina — não tem nada a ver com a potência emancipadora das forças produtivas descrita por Marx. A base produtiva do socialismo deve mesmo estar posta a priori ou qualquer pretensão revolucionária humana será sempre quixotesca, como este autor já apontava nos Grundrisse.

\section{BIBLIOGRAFIA}

ANTUNES, R. Adeus ao trabalho?: Ensaio sobre as metamorfoses e a centralidade do mundo do trabalho. São Paulo: Cortez;: Campinas: Unicamp, 1995.

Os Sentidos do Trabalho: ensaio sobre a afirmação e a negação do trabalho. $5^{\mathrm{a}}$. ed. São Paulo: Boitempo, 2001.

BENAKOUCHE, R. A transnacionalização do capital. Revista de Administração de empresas, Rio de Janeiro, v. 20, n. 1, p. 79-90, Jan 1980.

BRAVERMAN, H. Trabalho e capital monopolista: a degradação do trabalho no século XX. Rio de Janeiro: Zahar Editores, 1977.

FAJNZYLBER, F. La industrialización trunca de América Latina. México: CET - Centro de economia transnacional: Editorial Nueva Imagen, 1983.

FERRO, J. R.; TOLEDO, J. C.; TRUZZI, O. M. S. Automação e trabalho em indústrias de processo contínuo. São Carlos: Universidade Federal de São Carlos, 1985. Mimeo.

FORD, H. Minha vida e minha obra. São Paulo: Companhia Editora Nacional, 1926.

GORZ, A. Adeus ao Proletariado - para além do socialismo. Rio de Janeiro: ForenseUniversitária, 1987. 
. Metamorfoses do Trabalho: crítica da razão econômica. São Paulo: Annablume, 2003.

GORZ et al. Crítica da divisão do trabalho. $3^{\text {a }}$. ed. São Paulo: Martins Fontes, 1996.

HOBSBAWM, E. J. A era dos extremos: o breve século XX 1914-1991. São Paulo: Companhia das letras, 2000.

LENIN, V. I. As tarefas imediatas do poder soviético. In: BERTELLI, A. R. Estado, ditadura do proletariado e poder soviético. Belo Horizonte: Oficina de livros, 1988.

LESSA, S. Trabalho e proletariado no capitalismo contemporâneo. $2^{\text {a }}$. ed. São Paulo: Cortez, 2011.

MARX, K. Grundrisse - Lineamientos fundamentales para la crítica de la economía política. México: Fondo de Cultura Económica, v. I, 1985a.

Grundrisse - Lineamientos fundamentales para la crítica de la economía política. México: Fondo de Cultura Económica, v. II, 1985 b.

Miséria da Filosofia. São Paulo: Centauro, 2001.

. O Capital. 19a . ed. Rio de Janeiro: Civilização Brasileira, v. I e II, 2003.

Manuscritos Econômico-filosóficos. São Paulo: Boitempo, 2004.

MÉSZÁROS, I. A teoria da alienação em Marx. São Paulo: Boitempo, 2006.

MORAES NETO, B. R. Marx, Taylor, Ford: as forças produtivas em discussão. São Paulo: Brasiliense, 1989.

. O século XX e a teoria marxista do processo de trabalho. Crítica Marxista, São Paulo, 15, n. 10, 2002. 71-84. 
Século XX e trabalho industrial: taylorismo/fordismo, ohnoísmo e automação em debate. São Paulo: Xamã, 2003.

PRIEB, S. O trabalho à beira do abismo: uma crítica marxista à tese do fim da centralidade do trabalho. Ijuí: Unijuí, 2005.

ROSDOLSKY, R. Gênese e Estrutura de O Capital de Karl Marx. Rio de Janeiro: EDUERJ, 2001.

SILVA, J. P. D. André Gorz: trabalho e política. São Paulo: Annablume; FAPESP, 2002.

WOMACK, J. P.; JONES, D. T.; ROOS, D. A máquina que mudou o mundo. Rio de Janeiro: Campus, 1992.

ZILBERSHEID, U. The marxian idea of abolition os labor - can it be revived? University of Massachusetts at Amherst: International Conference Marxism (mimeo), 2000.

\footnotetext{
${ }^{1}$ Doutor em sociologia pela UNICAMP. Professor adjunto do Departamento de Pedagogia - Universidade Estadual do Oeste do Paraná - UNIOESTE. Email: mgsociais@ yahoo.com.br

${ }^{2}$ Este trabalho parte de um resumo do segundo capítulo de minha dissertação defendida ainda no mestrado e foi apresentado no IX Seminário de saúde do trabalhador, ocorrido na UNESP de Franca em 2015.

${ }^{3}$ Cf. (ANTUNES, 1995), (LESSA, 2011), (SILVA, 2002), (PRIEB, 2005).

${ }^{4}$ Cf. (SILVA, 2002) e (PRIEB, 2005).

${ }^{5}$ No caso, trata-se da desqualificação promovida pelo taylorismo e pelo fordismo que, como fora mostrada pelo próprio Henry Ford, não exige do operário nada mais do que movimentos ritmados e parciais que se aprende em poucos dias: "A maioria dos homens que se apresentam em nossa fábrica não possuem especialidade nenhuma e em horas ou dias aprendem o seu ofício. E se não o aprendem é que não prestam para nada" (FORD, 1926, p. 77).

${ }^{6}$ Sobre estes temas ligados ao taylorismo e despotismo, conferir também (GORZ et Al., 1996).

${ }^{7}$ Daí sua proximidade de pensadores como Ivan Illich, que grande influência exerceu sobre Gorz neste período.

${ }^{8}$ Assim diz Gorz em seu livro: "O desenvolvimento das forças produtivas do capitalismo é funcional apenas com relação à lógica e às necessidades do capitalismo. Esse desenvolvimento não somente não cria a base material do socialismo como lhe cria obstáculos. As forças produtivas desenvolvidas pelo capitalismo trazem a sua marca impressa a tal ponto que não podem ser geradas ou colocadas em operação segundo uma racionalidade socialista" (GORZ, 1987, p. 26). Tal debate em nosso meio ficou conhecido como a crítica à neutralidade da técnica. Epíteto este que de forma semântica já nos leva a equívocos de simplificações grosseiras e pouco dialéticas. Esperamos tratar disso ao longo deste artigo.
} 
${ }^{9}$ Cabe aqui ressaltar a grande confusão que teóricos do fim do trabalho fazem a respeito da categoria trabalho e da categoria emprego. Nesse sentido, não há apogeu ou crise da sociedade do trabalho, mas do emprego. Conservamos apenas nome por ser o mote de muitos destes autores.

${ }^{10}$ Uma opinião contrária a esta pode ser vista no artigo de Simon Clarke intitulado: Crise do fordismo ou crise da socialdemocracia? (Cf. CLARKE, 1991).

${ }^{11} \mathrm{~A}$ discussão sobre a correção da tese keynesiana não pode ser tratada aqui devidamente e nem é esta a pretensão. Cabe apenas um apontamento e uma indagação se a política econômica de um real gasto do Estado em obras e políticas sociais e de incentivo teria, sozinha, conseguido alavancar este crescimento sem a complexa situação envolvendo vários fatores como a reconstrução da Europa no pós-guerra e daí a enorme demanda, tanto de infraestrutura quanto de bens de consumo. E principalmente talvez uma base produtiva altamente concentradora de trabalho vivo, como é o caso da indústria metalmecânica e seus inerentes processos tayloristas e fordistas. Em caso negativo, explica-se talvez a incapacidade da esquerda que ascendeu ao poder não fazer nada mais que gerir os negócios da burguesia aplicando a mesma agenda neoliberal de forma escamoteada.

\begin{abstract}
${ }^{12}$ Não desconsideramos aqui os diversos fatores confluentes para a crise de 70 , tais como a política oligopolista adotada pelos países produtores de petróleo e principalmente o processo de transnacionalização do capital, que tem seu ponto de inversão crucial em 1971. "[...] Segundo relatório das Nações Unidas, em 1971 a produção internacional (ou seja, o valor da produção efetuada fora das fronteiras, pelas filiais das firmas nacionais) excedeu o montante das exportações (BENAKOUCHE, 1980). Esse movimento, como veremos, fortalece o argumento daqueles que dirão que o volume de trabalho vivo que se reduz nos países desenvolvidos será compensado pelo volume estimulado nos países que receberão investimentos e sediarão parte destes capitais transnacionais.

${ }^{13}$ Para usarmos um jargão trotskista.

${ }^{14}$ A tese do "fim do trabalho", assim concebida equivocadamente, continua aberta segundo nosso juízo. O fenômeno do assalariamento se amplia, tanto quanto a proletarização de outros setores. O conceito de trabalhador coletivo e de trabalho produtivo no sentido capitalista também abarca novos campos de trabalho. $\mathrm{O}$ desemprego nos países desenvolvidos da década de 80 e 90 é compensado extranacionalmente em parte pela mundialização do capital num primeiro momento, enquanto o capital podia encontrar farta mão de obra semiqualificada e sem tradição de luta e sindicalização em outras partes do mundo. Mas em parte esse movimento também se altera nos países que inicialmente abrigaram esta migração de capitais. A automação tende a se generalizar, mas é uma equação mais complexa envolvendo custos e política salarial, como se viu nas grandes montadoras do ABC. O emprego de tecnologias obedece a uma proporção racional cuja razão inversa é a oferta de mão de obra qualificada e barata. Mesmo no interior de uma fábrica, a adoção de uma tecnologia automática pode obedecer ao mesmo critério custo-benefício. O capital não vê qualquer obstáculo moral em empregar um trabalhador em serviços de risco se o pagamento de indenizações for muito inferior á implantação do mesmo serviço automatizado.
\end{abstract}

${ }^{15}$ Cf. (MORAES NETO, 2003) e (FERRO; TOLEDO; TRUZZI, 1985).

${ }^{16}$ Automação das Máquinas-Ferramenta Universais com base eletromecânica.

${ }^{17}$ Automação das Máquinas-Ferramenta de Controle Numérico Computadorizado com base microeletrônica.

${ }^{18}$ Proporcionado pela redução da jornada de trabalho garantida pela automação.

${ }^{19}$ Ainda que boa parte dos apontamentos feitos por Coriat esteja no capítulo XII e não XIII, como quer fazer crer.

${ }^{20}$ Sobre isso, Cf. (MARX, 1985a), (MARX, 1985b) e (ZILBERSHEID, 2000).

${ }^{21}$ Para entender o conceito de homem em Marx, tanto na relação de produção como na de apropriação, sugerimos (MARX, 2004).

${ }^{22}$ Conceito hoje pensado de forma pejorativa como produto filosófico anistórico.

RECEBIDO EM: Abril de 2016

APROVADO EM: Junho de 2016 